\title{
O DESENVOLVIMENTO INFANTIL AOS DOIS ANOS: CONHECENDO AS HABILIDADES DE CRIANÇAS ATENDIDAS EM UM PROGRAMA DE SAÚDE MATERNO-INFANTIL
}

CHILD DEVELOPMENT AT TWO YEARS OLD: LEARNING ABOUT CHILDREN'S SKILLS UNDER THE ASSISTANCE OF A MATERNAL AND CHILD HEALTH CARE PROGRAM

EL DESARROLLO INFANTIL A LOS DOS AÑOS: CONOCIENDO LAS HABILIDADES DE NIÑOS QUE ASISTEN A UN PROGRAMA DE SALUD MATERNO-INFANTIL

Carolina Sarzi Ledur ${ }^{*}$

Edinara Zanatta*

Caroline Rubin Rossato Pereira**

Dorian Mônica Arpini ${ }^{* * *}$

Maria Lucia Macari ${ }^{* * *+*}$

Patrícia Jovasque da Rocha*****

\begin{abstract}
RESUMO
O segundo ano de vida é um período de significativa importância no desenvolvimento infantil devido às rápidas conquistas que ocorrem nessa época. Este estudo teve como objetivo explorar as aquisiçóes de desenvolvimento percebidas pelas mães em crianças que haviam completado 2 anos de vida. $\mathrm{O}$ estudo configurou-se como qualitativo, tendo participado dele cinco díades mães-filhos, cujas crianças estavam na faixa etária entre 23 e 26 meses. As participantes responderam a um questionário de contextualização familiar e a uma entrevista semiestruturada, e foram realizados dois momentos de observação da relação mãe-filho. Os resultados foram analisados conforme o método de análise de conteúdo, por meio das seguintes categorias: linguagem, habilidades cognitivas, habilidades motoras e habilidades socioemocionais. Os resultados apontaram o desenvolvimento dentro do esperado para essa faixa etária e o olhar atento das mães acerca do desenvolvimento de seus filhos.
\end{abstract}

Palavras-chaves: Desenvolvimento infantil. Relaçōes familiares. Infância.

\footnotetext{
Texto recebido em 10 de novembro de 2015 e aprovado para publicação em 14 de junho de 2016.

"Psicóloga graduada pela Universidade Federal de Santa Maria (UFSM), residente em Saúde da Família e Comunidade na Escola GHC. E-mail: carolinasarzi@gmail.com.

"Mestra em Psicologia da Saúde pelo Programa de Pós-Graduação em Psicologia da UFSM, graduada em Psicologia pela UFSM. E-mail: edi.zanatta@hotmail.com.

***Doutora e mestra em Psicologia pela Universidade Federal do Rio Grande do Sul (UFRGS), doutorado sanduíche (UFRGS/ University of Michigan), especialista em Terapia de Casal e Família pelo Instituto da Família de Porto Alegre, graduada em Psicologia pela UFSM. E-mail: carolinerrp@gmail.com.

"*** Pós-doutora em Psicologia pela Universidade de Lisboa, doutora em Psicologia Social pela Pontifícia Universidade Católica de São Paulo (PUC São Paulo), mestra em Educação Brasileira pela UFSM, graduada em Psicologia pela Universidade de Passo Fundo.E-mail: monica.arpini@gmail.com.

${ }^{* * * * *}$ Mestranda no Programa de Pós-Graduação em Psicanálise: Clínica e Cultura da UFRGS, na linha de pesquisa psicanálise e cultura, psicóloga graduada pela UFSM. E-mail: marrymlm@gmail.com.
} 


\begin{abstract}
The second year of life is a period of significant importance in a child's development due to fast occurring achievements in this period. This study meant to explore the developmental acquisitions in children who had completed 2 years of age, noticed by their mothers. It turned out to be a qualitative study, involving five mother-child pairs. The children were between 23 and 26 months old. The participants answered a questionnaire on family contextualization, and a semi-structured interview, in addition to two moments of observation focusing on the mother-child relationship. The results were analyzed according to the method of content analysis, approaching the following categories, language, cognitive skills, motor skills and social-emotional skills. The results showed the development as expected for this age group and the mothers' watchful eyes at their children's development.
\end{abstract}

Keywords: Child development. Family relationship. Childhood.

\begin{abstract}
RESUMEN
El segundo año de vida es un período de significativa importancia en el desarrollo infantil debido a los rápidos logros que ocurren en esta época. Este estudio tuvo como objetivo explorar las adquisiciones del desarrollo percibidas por las madres de los niños que habían completado 2 años de vida. El estudio se configuró como cualitativo. Participaron cinco díadas madre-hijo, cuyos niños tenían entre 23 y 26 meses. Las participantes respondieron a un cuestionario sobre el contexto familiar, una entrevista semiestructurada y fueron realizadas observaciones en dos momentos de la relación madre-hijo. Los resultados fueron analizados según el método de Análisis de Contenido, utilizando las siguientes categorías: lenguaje, habilidades cognitivas, habilidades motoras y habilidades socio-emocionales. Los resultados mostraron que el desarrollo fue el esperado para este grupo de edad y que las madres tienen una atenta mirada sobre el desarrollo de sus hijos.
\end{abstract}

Palabras clave: Desarrollo infantil. Relaciones familiares. Infancia.

\title{
1 INTRODUÇÃO
}

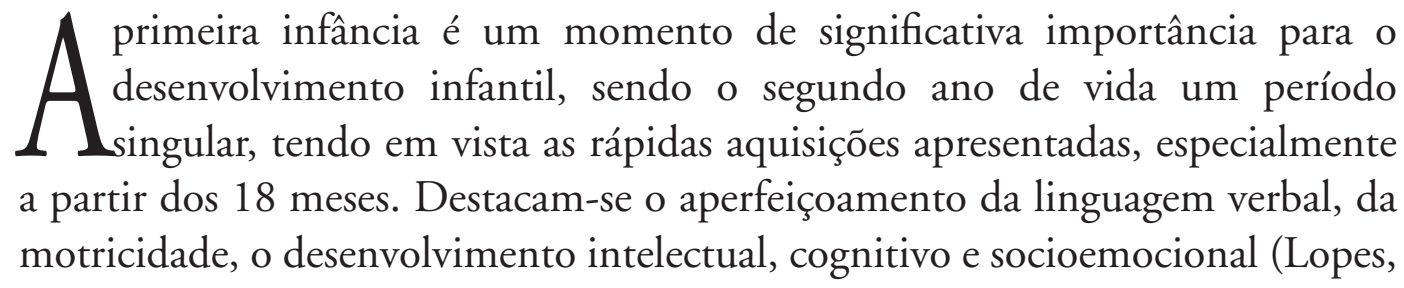


Vivian, Oliveira, Silva, Piccinini, \& Tudge, 2009), aspectos que devem ser compreendidos de maneira global e interligadas (Lopes et al., 2012).

A família também tem um papel fundamental no que concerne aos cuidados e estímulos necessários ao crescimento e desenvolvimento da criança, bem como para o surgimento do vínculo pais-filhos (Andrade et al., 2005; Dourado, Carvalho \& Lemos, 2015). Dessa forma, o ambiente familiar é de grande importância, pois é nele que a criança estabelece a relação com o mundo e com as pessoas, garantindo sua formação e qualidade de vida social, moral, psicológica e cultural (Paula, Pires, Mascarenhas, Costa \& Brito, 2013).

Com relação às habilidades motoras, aos 2 anos, as crianças são descritas pelos manuais clássicos de desenvolvimento como sendo capazes de correr, caminhar de costas e pular (Papalia \& Olds, 2000). Elas, em geral, têm muita energia, ao mesmo tempo em que ainda não desenvolveram bem as noções de altura, de perigo e de cuidados consigo mesmas (Newcombe, 1999). De acordo com Papalia e Olds (2000), não é necessário ensinar habilidades motoras básicas para os bebês, eles somente necessitam de espaço para se movimentar e liberdade para descobrir o que podem fazer.

No que tange à linguagem oral, para Arnold e Colburn (2011), o período entre o nascimento e os 3 anos de idade pode ser considerado o mais crucial. Até os 18 meses, o vocabulário médio da criança inclui entre 3 e 50 palavras. Após esse período, ocorre o que Lenneberg (1967, citado por apud Biaggio, 2003) chamou de "explosão de nomeação", de modo que, ao completar 3 anos, a criança geralmente tem um vocabulário de mil palavras, sendo que conhece e compreende outras 2 ou 3 mil (Biaggio, 2003). A linguagem é um fator de extrema importância para o desenvolvimento psicológico da criança, apresentando uma estreita relação com o meio no qual ela está inserida e com os aspectos cognitivos (Flores, 2012).

Atrelado ao desenvolvimento cognitivo infantil está o surgimento da capacidade de autoconsciência da criança. Nesse sentido, aos 2 anos, a capacidade de simbolizar já pode ser experienciada pela criança. Essa característica é notória pelas brincadeiras, sendo que o pequeno manipula os objetos de forma a reproduzir atitudes manifestadas pelos adultos com os quais ele convive. Nesse momento, a criança pode começar a substituir a si própria por um brinquedo, que assume um papel ativo na brincadeira, inclusive, podendo fazer de conta que é outra pessoa (Manfro, Maltz, \& Isolan, 2001).

No que diz respeito às aquisiçôes socioemocionais, entendidas aqui como a crescente autonomia e independência da criança na relação com sua mãe, estas se relacionam tanto com o desenvolvimento motor como com o desenvolvimento 
linguístico e cognitivo (Lopes et al., 2012; Papalia \& Olds, 2000; Mahler, 1993). Nesse sentido, Mahler (1993) aponta que a aquisição da livre locomoção em posição ereta e as crescentes capacidades cognitivas acabam por resultar no alcance do primeiro nível de identidade: o de ser uma pessoa individual, separada de sua mãe e cada vez mais autônoma. Dessa forma, as crianças passam a buscar uma independência cada vez maior das pessoas às quais são apegadas (Papalia \& Olds, 2000). De acordo com os estudos realizados por Lopes et al. (2009, 2012), as crianças afirmam sua independência pela manifestação de opiniões e escolhas próprias, de "teimosia" e "insistência", assim como pela expressão de preferências ligadas a diversas áreas do desenvolvimento, como a alimentação, os cuidados pessoais e de higiene.

Com o crescente desenvolvimento das habilidades socioemocionais, as crianças conseguem permanecer períodos cada vez mais longos longe de suas mães e, até mesmo, separar-se delas ativamente. Nesse sentido, os estudos realizados por Mahler (1993) indicaram que, ao mesmo tempo em que a criança não gosta de ser deixada para trás e precisa saber onde a mãe está, ela consegue deixar a mãe para realizar as próprias atividades. Ainda que a criança consiga distanciar-se fisicamente da mãe por períodos cada vez maiores, os momentos de dependência ficam mais frequentes e intensos. Mahler (1993) referiu-se a essa fase como "ambitendência". Assim como a criança afasta, por meio da agressividade e do uso frequente do "não", as invasões feitas à sua autonomia recentemente alcançada, o medo de perder o objeto amado (a mãe) torna-se cada vez mais presente, intensificando a reaproximação da dupla. Dessa forma, conforme aumenta a consciência de separação da criança, estimulada pelo seu desenvolvimento físico e cognitivo, aumentam também a ansiedade de separação e os comportamentos de aproximação ativa.

Assim, muitas mudanças, avanços e crescimentos são esperados para essa etapa de vida, trazendo com eles também desafios às crianças e àqueles que com elas convivem, de modo especial, seus pais e cuidadores. Além disso, destacase que o desenvolvimento infantil ocorre em estreita relação com o meio no qual a criança e seus cuidadores estão inseridos, de forma que características socioculturais e contextuais interferem nesse processo e no modo como ele é percebido por aqueles que cercam as crianças. Dessa forma, este estudo teve como objetivo explorar as aquisições de desenvolvimento percebidas por mães de bebês de 2 anos de vida participantes de um programa de saúde maternoinfantil de uma Unidade Básica de Saúde (UBS). 


\section{MÉTODO}

\subsection{Participantes}

Integraram este estudo cinco díades mãe-bebê, cujos filhos se encontravam na faixa etária entre 23 e 26 meses no momento do primeiro contato para a pesquisa. Tais díades fazem parte de um estudo maior, intitulado "Promoção de saúde a bebês atendidos em uma unidade básica de saúde: um estudo voltado para indicadores clínicos de risco ao desenvolvimento infantil”, bem como foram acompanhadas por um grupo de psicólogas e enfermeiras em um programa materno-infantil de uma unidade de saúde do interior do Rio Grande do Sul. A maioria das participantes tinha como ocupação o trabalho no lar. Apenas uma mãe (M3) tinha voltado a trabalhar formalmente após o término da licença maternidade. Dessa forma, elas são as principais responsáveis pelos cuidados das crianças, vivenciando intensamente o processo de desenvolvimentos dos filhos. $\mathrm{Na}$ tabela 1, podem ser observados os dados sociodemográficos das participantes.

Tabela 1 - Dados sociodemográficos das participantes

\begin{tabular}{|c|c|c|c|c|c|c|c|}
\hline $\begin{array}{l}\text { Mães } \\
\text { (M) }\end{array}$ & $\begin{array}{c}\text { Idade do } \\
\text { bebê }\end{array}$ & $\begin{array}{l}\text { Idade } \\
\text { da mãe }\end{array}$ & $\begin{array}{l}\text { Ocupação da } \\
\text { mãe }\end{array}$ & $\begin{array}{l}\text { Idade } \\
\text { do pai }\end{array}$ & $\begin{array}{c}\text { Ocupação do } \\
\text { pai }\end{array}$ & $\begin{array}{l}\text { Número de } \\
\text { irmãos }^{1}\end{array}$ & $\begin{array}{c}\text { Idade } \\
\text { dos } \\
\text { irmãos }\end{array}$ \\
\hline M1 & $\begin{array}{c}23 \\
\text { meses }\end{array}$ & 27 anos & Dona de casa & 30 anos & $\begin{array}{l}\text { Caixa em } \\
\text { posto de } \\
\text { combustível }\end{array}$ & 3 irmãos & $\begin{array}{c}10 \\
\text { anos } \\
7 \text { anos } \\
4 \text { anos }\end{array}$ \\
\hline M2 & $\begin{array}{c}24 \\
\text { meses }\end{array}$ & 29 anos & Dona de casa & 37 anos & Construtor & 0 irmãos & $\longrightarrow$ \\
\hline M3 & $\begin{array}{c}26 \\
\text { meses }\end{array}$ & 23 anos & $\begin{array}{l}\text { Atendente de } \\
\text { supermercado }\end{array}$ & 26 anos & $\begin{array}{l}\text { Torneiro } \\
\text { mecânico }\end{array}$ & 1 irmã & 6 anos \\
\hline M4 & $\begin{array}{c}24 \\
\text { meses }\end{array}$ & 40 anos & Dona de casa & 43 anos & $\begin{array}{c}\text { Mestre de } \\
\text { obras }\end{array}$ & 2 irmãos & $\begin{array}{c}20 \\
\text { anos } \\
13 \\
\text { anos }\end{array}$ \\
\hline M5 & $\begin{array}{c}26 \\
\text { meses }\end{array}$ & 27 anos & Dona de casa & 29 anos & $\begin{array}{l}\text { Serviços } \\
\text { gerais }\end{array}$ & 1 irmã & $\begin{array}{c}10 \\
\text { anos }\end{array}$ \\
\hline
\end{tabular}

Fonte: elaborado pelas autoras.

\subsection{Instrumentos}

Para a coleta de dados, foi utilizada uma entrevista com as mães, de caráter qualitativo e do tipo semiestruturada, seguindo como roteiro os seguintes tópicos 
guia:
a) o dia a dia com o bebê;
b) amamentação;
c) comunicação mãe-bebê;
d) interação mãe-bebê; e
e) limites e regras.

Tal perspectiva seguiu os preceitos de Gaskell (2002), autor que entende que a entrevista semiestruturada fornece os dados básicos para a compreensão das relações que existem entre os atores sociais e a situação em que eles se encontram, sendo possível chegar a uma compreensão detalhada das crenças, atitudes, valores e motivações das pessoas naquele contexto social específico.

Além da entrevista, foi realizado o preenchimento de um questionário de contextualização das díades, contendo a identificação do bebê e dos pais (nomes, idades, ocupações) e dados sobre a configuração familiar (número de irmãos do bebê e idades, outros familiares que residiam com a díade). Posteriormente foram realizados dois momentos de observação da interação mãe-criança, sendo o primeiro filmado mediante a autorização das participantes. $\mathrm{O}$ uso do vídeo tem como vantagem o fato de que outros pesquisadores também podem ter acesso ao material coletado, garantindo uma maior neutralidade dos dados. Além disso, o vídeo permite que haja um exame aprofundado do material a ser analisado, pois pode ser revisto quantas vezes forem necessárias (Belei, Gimeniz-Paschoal, Nascimento, \& Matsumoto, 2008).

A primeira observação da díade, que foi filmada, ocorreu na Unidade Básica de Saúde (UBS), na sala do Programa da Criança. Essa observação teve duração de aproximadamente 20 minutos, sendo realizada após a entrevista com a mãe. Para essa observação, a mãe e a criança foram convidadas para brincarem no centro da sala, em um ambiente previamente preparado com brinquedos variados (bola, bonecos, brinquedos de montar, livros). Por essa indicação, buscou-se ter acesso a aspectos do desenvolvimento infantil presentes nas brincadeiras. Contudo essa abordagem foi apenas uma orientação, respeitando-se a forma de interação das díades. Participaram também desse momento de coleta de dados dois pesquisadores, um que realizou a filmagem e outro que estava integrado à díade. A participação do pesquisador ficou restrita à sua inserção na cena, ou seja, tinha-se a intenção de que a proximidade do pesquisador abrandasse os efeitos da filmagem e da observação. A equipe de pesquisa partiu, assim, da compreensão de que esses efeitos ficariam mais acirrados se os pesquisadores se mantivessem isolados da cena. 
A segunda observação foi realizada aproximadamente uma semana após a primeira, na residência dos participantes, com o intuito de observar a relação mãe-bebê no ambiente familiar. Nesse momento, o foco esteve sustentado pelos aspectos manifestados na primeira observação, a fim de que se pudesse observálos no contexto doméstico e usual à díade. Dessa forma, partiu-se do pressuposto de que a criança, estando na sua casa, com seus brinquedos e em seu ambiente, apresentar-se-ia de forma mais natural. Esse momento teve a duração de aproximadamente 40 minutos, também com a presença de dois pesquisadores. $\mathrm{O}$ registro dessa segunda observação foi realizado na forma de relato escrito realizado pelos pesquisadores que haviam feito a visita. Para esse momento, foi também preparada uma devolução para cada díade, levando-se em conta aspectos abordados pelas mães nas entrevistas e na observação, valorizando-se características do desenvolvimento como linguagem, independência, habilidades motoras, cognitivas e socioemocionais. Foram abordadas também questóes relativas à compreensão de regras e limites. Utilizaram-se exemplos das falas das mães e pontos observados na interação feita na UBS para dialogar com elas no momento da devolutiva. Destaca-se que a devolução, embora tenha abordado as questôes presentes nas categorias deste estudo, foi preparada individualmente, de forma a abarcar as singularidades de cada díade. Nesse dia, também foi entregue um DVD com a gravação da primeira observação e uma cartilha com informações acerca da relação pais-bebê, a qual foi resultado do estudo maior referente à promoção de saúde a bebês.

\subsection{Procedimentos}

O estudo foi realizado junto a uma unidade de atenção básica de uma cidade do interior do Rio Grande do Sul. A análise dos dados foi conduzida por meio da análise de conteúdo qualitativa (Bardin, 2010; Gomes, 2001), buscandose realizar uma articulação entre os dados obtidos por meio da triangulação das técnicas de entrevista e observação. De acordo com Barbour (2009), a triangulação permite ao pesquisador utilizar-se de dados obtidos com diferentes instrumentos, o que, para a pesquisa qualitativa, torna-se interessante, tendo em vista que esta não busca a confirmação e sim prospera levando em consideração as singularidades encontradas com os dados.

No que tange à análise de conteúdo, essa é uma importante modalidade de análise dedados para estudos qualitativos, cujoobjetivo éexplorar em profundidade o fenômeno por meio das falas dos sujeitos entrevistados (Richardson, 2008). Os procedimentos de análise neste estudo incluíram a transcrição e leitura individual de cada entrevista por cada membro da equipe de pesquisa, seguida 
da análise conjunta do material. O mesmo procedimento se repetiu com relação às observações. Em um primeiro momento, as pesquisadoras assistiram à filmagem de cada díade, discutindo e analisando os aspectos relacionados ao desenvolvimento do filho. Procurou-se, então, relacionar os aspectos presentes na filmagem com o material proveniente das entrevistas. Esse procedimento foi realizado para cada díade, sendo que, a partir dessa etapa, foi realizada, por uma visita domiciliar, a devolução às mães participantes. A devolução e a observação realizada na visita domiciliar também foram relatadas e discutidas uma a uma pela equipe, de modo que, ao fim, todo o material foi integrado e analisado em sua totalidade.

Destaca-se que essa pesquisa está respaldada nas Diretrizes e Normas Regulamentadoras de Pesquisa Envolvendo Seres Humanos (Resolução no 466, 2012) e na Resolução no 016/2000 do Conselho Federal de Psicologia, tendo sido aprovada pelo comitê de ética de uma universidade pública. Ainda, como este estudo teve como população-alvo crianças e suas mães, foi utilizado o Termo de Consentimento Livre Esclarecido (TCLE), que foi assinado pelas mães das crianças. Além deste TCLE, as mães também assinaram o termo de autorização de uso de imagem.

\section{RESULTADOS E DISCUSSÃO}

Com base na análise de conteúdo qualitativa, os resultados deste estudo serão apresentados em cinco categorias, a saber: habilidades motoras, linguagem, habilidades cognitivas e habilidades socioemocionais. A construção dessas categorias esteve ancorada nos manuais de desenvolvimento infantil e na revisão da literatura sobre a temática (Brazelton, 1994; Lopes et al., 2009, 2012; Newcombe, 1999; Papalia \& Olds, 2000).

\subsection{Habilidades motoras}

No que tange à motricidade das crianças, a agitação foi uma característica empregada pelas mães para descrever o comportamento de seus filhos neste momento. As mães referiram que as crianças não paravam de se movimentar o dia todo, andando, correndo, subindo e descendo, e até dançando:

"Ela não para. Ela sobe em tudo. Ela sobe em cima do muro. Ela se pendura no portão. Ela mexe com os cachorros. Ela mexe com um e outro na rua. [. . .] É o dia inteiro assim!” (M1)

“É bem agitada, ela não sossega um minuto, tá sempre fazendo uma coisa e outra!" (M3) 
“[movimenta-se] bastante, o dia inteiro. Pra parar, só quando tá dormindo.” (M4)

Segundo as mães, as crianças também apresentavam comportamentos de exploração do ambiente a sua volta, mexendo nos objetos e colocando objetos na boca, o que era chamado por elas de "bagunçar" ou "fazer arte":

"Ela mexe em tudo quanto é pecinha, bota a mão ali. Ela gosta de tá mexendo, fuçando e bagunçando!” (M1)

"Quando ele tá muito tempo quieto, alguma arte ele tá fazendo. Ele levanta, vai na geladeira, mistura tudo que tem dentro. Liga as bocas do fogão, desliga o botijão. [. . .] Engoliu um parafuso estes dias de tão arteiro!" (M5)

Esses resultados estão de acordo com os estudos de Lopes et al. (2009, 2012), que investigaram mães de crianças nas faixas etárias de 18 a 20 meses e 24 a 28 meses de idade da cidade de Porto Alegre-RS. Segundo as autoras, entre as crianças de 18 a 20 meses, as mães perceberam uma crescente atividade e independência física, passando a apresentar mais agilidade, segurança e capacidade para explorar o ambiente (Lopes et al., 2009). Tal independência física é essencial para o desenvolvimento motor da criança, que é conquistado justamente pela exposição desta a oportunidades de desenvolvimento, deixando-a livre para descobrir o ambiente que a cerca (Pereira, Saccani, \& Valentini, 2016). Entretanto, ao completarem 2 anos ( 24 a 28 meses), a maior atividade física das crianças foi associada pelas mães a características de agitação e inquietação (Lopes et al., 2012). A esse respeito, pode-se supor que esta seja uma etapa especialmente desafiadora para as mães e demais cuidadores, pois a motricidade se torna muito evidente no segundo ano, quando o bebê pode se deslocar e experimentar, por meio de gestos mais precisos, seu ambiente (Mellier, 2013). Cabe ressaltar que a exposição da criança aos estímulos presentes em seu ambiente, com a possibilidade de exploração do local que a rodeia, pode minimizar os efeitos de possíveis fatores biológicos de risco ao desenvolvimento (Dourado, Carvalho \& Lemos, 2015; Pereira, Saccani, \& Valentini, 2016).

Associado à agitação motora, ao desejo de movimentar-se e explorar o ambiente, as entrevistadas referiram que seus filhos apresentavam dificuldade em fixar seu interesse e atenção, por um período mais longo, em uma mesma atividade: "Ela não se entrete (sic). Tudo ela pega, brinca e, dali a pouco, não quer mais. Ela não se concentra” (M1).

Segundo as mães, isso estaria mais acentuado neste momento:

“Tem um desenho que ela gostava, às vezes, ela parava. Só que agora ela não para nem pra 
olhar esse desenho." (M1)

"Quando ela era menor, ela até gostava mais de olhar televisão. Agora ela não para muito pra olhar. Ela prefere tá na função de correr pra cá e pegar uma coisa.” (M2)

$\mathrm{Na}$ observação da interação mãe-criança, foi possível perceber que, enquanto algumas crianças alternavam continuamente seu foco de interesse na brincadeira, explorando o ambiente à sua volta, outras eram capazes de se engajar em uma brincadeira focada (ex.: desenho ou montagem), por um período considerável, de mais de cinco minutos (M4, M5). Contudo isso ocorreu em um contexto em que a mãe estimulava e envolvia-se continuamente na brincadeira com a criança. Sobre isso, Dourado, Carvalho e Lemos (2015) ressaltam a importância de os pais compartilharem seu tempo livre com os filhos, por meio de atividades culturais e educacionais, favorecendo, assim, o "Desenvolvimento cognitivo, o desempenho escolar e o ajustamento interpessoal” da criança (p. 96).

Dadas as capacidades de exploração das crianças e sua crescente autonomia associada à imaturidade no controle dos impulsos, pode ser difícil para elas abrir mão de alguns estímulos e manter sua atenção concentrada em uma mesma tarefa por um longo período. Segundo Weijer-Bergsma, Wijnroks, e Jongmans (2008), as crianças pequenas precisam desenvolver habilidades de selecionar aquilo em que prestar atenção e a que responder, além de aprender a persistir e completar tarefas apesar dos obstáculos e das distrações.

Ainda com relação à agitação das crianças pequenas, em uma perspectiva psicanalítica, Mellier (2013) afirmou que é como se a criança falasse "em ações" aquilo que pensa ou que ainda não consegue dizer totalmente em palavras. Para a autora, quando ainda representa em ações o mundo que cerca os pequenos, a agitação pode traduzir aquele que a criança busca expressar, encontrando na ação uma via de existir.

\subsection{Linguagem}

No momento da realização do estudo, todas as crianças já estavam fazendo uso da linguagem verbal. Algumas foram consideradas como tendo falado cedo e com facilidade em relação às demais:

“Todo mundo ficou apavorado que no um aninho dela; ela já era bem falante.” (M2)

"Nessa parte a gente acha que ela é bem esperta em compensação às outras crianças que têm a mesma idade." (M3) 
"Eu acho que até tá demais pro tamanho dele." (M4)

Por outro lado, outras crianças demoraram um pouco mais para começar a falar, o que foi motivo de preocupação para uma mãe:

"Eu disse: 'Vou colocar um pinto na boca desse guri. Bota um pinto que pia, e ele começa a falar'. Depois que começou a falar: 'Não vou botar mais, agora tá falando demais'. [. . .] O medo da gente era que chorava e tinha que adivinhar o que ele tinha” (M5).

Percebe-se a importância da expressão verbal dos filhos para que a mãe possa compreender suas necessidades. Além disso, chama a atenção o quanto as mães usam o conhecimento que têm sobre outras crianças para balizar o desenvolvimento de seu filho, embora todos eles estivessem, a seu tempo, comunicando-se sem dificuldades.

Segundo Lopes et al. (2009), mães de crianças de apenas 18 meses já destacam suas capacidades de expressar, por meio de palavras, o que necessitam. Já crianças mais velhas, em torno dos 2 anos de idade, passam a se mostrar ativas na tentativa de serem compreendidas por seus genitores, utilizando a linguagem verbal para contar ou compartilhar situações vivenciadas (Lopes et al., 2012), além de contribuir para o estabelecimento e manutenção dos relacionamentos com os demais (Newcombe, 1999).

Contudo, considerando que as crianças apresentavam idade média de 25 meses, a linguagem verbal ainda se mostrava como uma aquisição recente e em pleno desenvolvimento: "Naquela de querer contar as coisas, ela dá uma atrapalhada. As vezes, ela chega e conta uma coisa, um pouco tu entende, um pouco não entende" (M2). Assim, fazia-se muito importante o uso concomitante de gestos e expressões não verbais para a comunicação: "Ela quer que tu saia da cama. Ela te dá teu chinelo, ela te puxa, ela te tira da cama" (M1). Percebe-se, como apontado por Brazelton (1994), que a linguagem gestual é observável nas crianças que falam, especialmente nos momentos em que elas não conseguem dizer exatamente, mediante palavras, o que estão querendo. $\mathrm{Na}$ observação da interação mãe-criança, foi possível perceber a importância do uso dos gestos pela criança na comunicação de seus desejos, apontando os brinquedos com os quais gostaria de brincar, puxando a mãe pela mão para levá-la aonde desejava, colocando na mão da mãe o brinquedo com o qual gostaria que ela brincasse.

Cabe destacar que a linguagem surge e se desenvolve em um contexto de interação (Biaggio, 2003). Assim, o desenvolvimento da linguagem está claramente associado à extensão em que os pais e demais cuidadores das crianças conversam com elas. Segundo Arnold e Colburn (2011), as experiências de 
conversação durante os primeiros 36 meses do bebê contribuem decisivamente para o desenvolvimento da linguagem oral. Além disso, Dourado, Carvalho e Lemos (2015) também apontaram como fator importante para o desenvolvimento da linguagem a exposição da criança a brinquedos diversos, fato que pôde ser observado nas díades participantes do estudo.

\subsection{Habilidades cognitivas}

Considerando-se que a linguagem é um importante marco para o desenvolvimento infantil, com a aquisição desta, percebe-se um aumento da capacidade de raciocínio da criança, o que favorece a capacidade de compreender e de se fazer compreender aos outros (Lopes et al., 2012). No que se refere às habilidades cognitivas, houve um reconhecimento materno do desenvolvimento dos filhos, referindo-se a eles como sendo crianças inteligentes: "Ela é bem inteligente. Até o bico dela, que é vermelho, ela diz: 'Mãe, cadê meu bico vermelho?'. Ela presta atenção em tudo que tu fala" (M2). Além disso, as mães consideravam a inteligência de seus filhos como superior ao esperado para a sua idade:

"O jeito de agir dele é de uma criança mais velha. Tudo ele olha, com uma certeza." (M4)

"Ela é muito esperta pra idade que ela tem. Às vezes, ela deixa de queixo caído a gente. Ela tem uma mente que, pra uma criança de 2 anos, é muito inteligente.” (M3)

Além disso, por meio das atitudes demonstradas pelos filhos, as mães atribuíam-lhes a capacidade de entendimento daquilo que lhes era comunicado: "Entende até demais. Ela entende porque, às vezes, tu tá falando com ela e ela te pergunta: 'Ah, isso a C [.. .] pode fazer?'” (M3). A capacidade de compreensão da criança se manifestou, inclusive, no entendimento de atividades de rotina do funcionamento da família (atribuições domésticas): "Ela mama, pega a mamadeira e guarda. A gente diz: 'Pode colocar lá em cima do armário', e ela levanta e vai: "Já botei pai"' (M2). "Quando ele termina de comer, ele pega o pratinho dele e leva lá na pia" (M4).

Por volta dos 2 anos, a criança adquire um senso de individualidade e autonomia. Nessa fase, ela se torna consciente de suas capacidades e vontades. Nessa etapa, a criança pode começar a descrever seu próprio comportamento enquanto o está executando, reconhecendo a si própria no espelho e afirmando a sua posse de objetos. Nesse momento, é comum que ela inclua em seu discurso palavras como "eu" e "meu", e usa seu próprio nome para referir-se a si mesma (Manfro, Maltz \& Isolan, 2001). 
O desenvolvimento das habilidades cognitivas dos filhos também foi perceptível para as mães através da capacidade imaginativa deles, expressa através da brincadeira simbólica:

"Adora livrinho, daí inventa as historinha dele: 'Ó, o cavalo do papai, ó, o cavalo do vovô!" (M4)

"Ela gosta de brincar com panelinha. Ela diz que vai fazer comida. E ela tem a xicrinha e ela gosta de dar pra gente: 'Vamos mamãe comer papa'. Boneca mesmo, ela gosta de nanar. Ela canta 'A cuca vai te pegar'." (M2)

Nesse sentido, na observação na casa da dupla M2, foi possível observar a brincadeira de faz de conta em que a criança estava brincando de cozinhar. Ela "preparou" e ofereceu para as pessoas que estavam na sala, entre elas, a pesquisadora, "bolo de morango e café". A criança manipulou objetos de forma a reproduzir atos observados em adultos, demonstrando a capacidade recentemente adquirida de imitar ações que não veem mais à sua frente.

\subsection{Habilidades socioemocionais}

Nesta categoria, buscou-se descrever os aspectos socioemocionais envolvidos no desenvolvimento infantil, expressos pelo processo de dependência e independência das crianças na relação com suas mães. $\mathrm{O}$ discurso materno indicou que as crianças apresentavam um saber sobre seus cuidados corporais, demonstrando certa independência em relação à mãe nos momentos de higiene:

"Ela já sabe que tem que tomar banho, ela vai pra banheira. Ela sabe que tem que dormir e escovar os dentes, ela já vai pro banheiro pra escovar os dentes.” (M1)

"Tu não fala que vai dar banho antes de tá com a roupinha pronta, porque tu falou em banho, ele se vai pro banheiro." (M4)

Corroborando com este estudo, a pesquisa realizada por Lopes et al. (2009) indicou que, pelas tomadas de iniciativa, as crianças realizam movimentos de independência nos momentos de higiene. $\mathrm{O}$ saber sobre o ritual e as regras de higiene facilitou que as crianças exercessem maior independência em relação às suas mães nesse momento.

No momento do contato com as mães, algumas das crianças faziam o uso da fralda, mas passavam por um processo de aprendizagem para deixarem de usá-la. Outra criança já havia deixado de usar a fralda. Nesse caso, foi possível 
perceber que a linguagem verbal apareceu como facilitadora: "Eu comecei a dizer pra ela pedir. Como ela falava bem, ela começava a pedir. Ela via o peniquinho e ela começava sentar no peniquinho. Ela foi se soltando e pedindo, pedindo" (M2). O treinamento higiênico associado à linguagem são consideradas duas conquistas importantes no desenvolvimento da autonomia e autocontrole, pois conforme as crianças conseguem expressar seus desejos, tornam-se mais independentes (Papalia \& Olds, 2000).

A hora das refeições também se configurou como um momento em que as crianças conseguiam exercer certa autonomia, mediante ações como comer sozinha, pegar o próprio alimento e sentar-se à mesa sem a ajuda de um adulto:

"Ela quer fazer muitas coisas sozinha. A colher ela quer pegar pra comer sozinha. O suco ela toma sozinha." (M1)

"É tudo com a mão dela. Ela mesma senta na mesa e vai comendo. Ela é bem independente já." (M2)

"Os iogurtezinho dele, ele já vai na geladeira pegar." (M4)

Assim, a criança assume um papel ativo na relação com seus cuidadores, demonstrando que pode exercer pequenas funções por conta própria. Além disso, o momento de alimentação também pode indicar um movimento de independência a partir da expressão de preferências por parte da criança (Lopes et al., 2009). A esse respeito, foi possível observar que as mães permitiam e incentivavam tal movimento por parte dos filhos: "O iogurte, às vezes, eu dou pra ela, ela come sozinha" (M1); "Um ano e meio por ai, a gente começou a deixar ela à vontade, largar tudo na mão dela. A banana, dava na mãozinha dela, e ela comia com a mão dela" (M2). A disposição da mãe para soltar e encorajar o filho a assumir atitudes independentes é importante para o desenvolvimento motor e psicológico da criança, pois favorece uma individuação saudável (Mahler, 1993; Papalia \& Olds, 2000; Pereira, Saccani, \& Valentini, 2016).

Ao mesmo tempo em que a alimentação se configurava como um momento de autonomia para a criança, as mães relataram que seus filhos estavam em aleitamento materno. Segundo Bowlby (2002), a amamentação ultrapassa a função nutritiva, pois o "bebê" passa mais tempo agarrado à mãe, acariciando e abocanhando-lhe o seio do que ingerindo o alimento proveniente do peito materno. Nesse sentido, as mães participantes do estudo demonstraram que o momento da amamentação, mais do que simplesmente alimentar as crianças, servia como fonte de segurança e proteção para elas, visto que se voltavam para 
o corpo materno: "Durante o dia não. Só se ele caiu ou alguém deu nele e ele tá chorando, e daí ele vem 'mamá. Se não, não" (M5); "Pra mim [amamentar], é tranquilo, porque acalma ela. É o momento que ela fica mais perto de mim" (M1). Entretanto, a amamentação no peito prevalecia nos períodos que antecediam o sono da criança e durante a noite: "Agora eu tô tentando tirar um pouquinho. Daí, de manhã, eu não dou muito, aí dou uma fruta, dou uma bolacha pra ela comer. Mas, de noite, quando eu chego, ela já vem: 'Quero teti' (M3). Nesse sentido, Lopes et al. (2012) apontaram que as crianças buscavam a presença materna e o contato físico, especialmente na hora do sono. Pode-se perceber que, no que se refere à alimentação, as crianças nessa faixa etária alternam momentos de maior e menor autonomia (Lopes et al., 2009, 2012; Mahler, 1993).

Conforme o relato das mães no momento da entrevista, todas as crianças dormiam no quarto de seus pais, contudo apresentavam variaçóes quanto à proximidade e dependência de suas mães durante a noite. Algumas crianças dormiam no próprio berço: "Dorme no mesmo quarto, mas ela dorme no berço desde nenê" (M2); "Ele dorme no berço. [. . .] Ele mesmo entra pro bercinho dele de noite" (M4). Outras crianças dormiam com seus pais, na cama do casal: "Dorme comigo, na mesma cama. Ele dorme a noite inteira no braço" (M5); "Ela sempre dorme comigo" (M1); "Ela dá um cochilo, quando ela se lembra que ela tá sozinha [no berço], ela não fica" (M3). Nesses casos, o aleitamento materno apareceu como principal justificativa para que a criança dormisse na mesma cama que a mãe:

"Pra dormir, eu tenho que deitar com ele, porque ele ainda mama no peito." (M5)

"Eu até tentei botar ela na cama separada, mas ela não fica. Eu acho que, por causa do peito, ela não fica. Ela pede, daí ela já vem se encostando, aí não fica sozinha.” (M3)

No que tange à autonomia das crianças expressa por sua capacidade de suportar pequenos afastamentos em relação às suas mães, algumas participantes do estudo indicaram que seus filhos conseguiam suportar a sua ausência, permanecendo tranquilos sob os cuidados de outras pessoas: "Fica bem faceira. [. . . ] A madrinha dela, de vez em quando, busca, e ela fica o dia inteiro na casa da madrinha. [. . . ] Vai, dá tchau, pega a mochila dela e sai" (M2); "Com a vó dele, ele te troca se tu deixar" (M4). Segundo Mahler (1993), nessa faixa etária, as crianças começam a gostar de permanecer períodos cada vez mais longos longe de suas mães ou cuidadoras. Para isso, as crianças começam a investir em relacionamentos com outros adultos como forma de tolerar as ausências da mãe.

As participantes do estudo relataram também que seus filhos começaram 
a demonstrar interesses por atividades não relacionadas a elas. Nesse sentido, foi possível observar que a filha da (M2) permaneceu brincando enquanto sua mãe (M2) mantinha um diálogo com a pesquisadora. Após pouco tempo sem a atenção materna, interveio, chamando-as e mostrando a boneca que tinha encontrado, a fim de conseguir o olhar delas. Segundo Mahler (1993), esse período do desenvolvimento é marcado pela ambivalência diante da separação, caracterizada pelo conflito de se afastar da mãe, ao mesmo tempo em que deseja se agarrar a ela.

\section{CONSIDERAÇÕES FINAIS}

Foi possível perceber, por este estudo, o olhar atento e interessado das mães acerca do desenvolvimento de seus filhos no que diz respeito ao desenvolvimento das habilidades motoras, de linguagem, cognitivas e socioemocionais. Nesse sentido, as mães comparavam as aquisições de seus filhos em relação a outras crianças, tentando balizar seu desenvolvimento conforme o que lhes parecia esperado para a faixa etária. Dessa forma, foi possível perceber que as mães se mostravam preocupadas com o desenvolvimento dos filhos, demonstrando o desejo de que a criança apresentasse um bom desempenho para a sua idade. Por outro lado, percebeu-se que as mães também compreendiam a singularidade do processo de desenvolvimento de seus filhos, indicando entender que as crianças têm ritmos particulares de desenvolvimento e que estes deveriam ser respeitados. Nesse sentido, elas ocupavam uma função muito mais de acompanhar e incentivar as aquisições da criança do que de buscar moldar ou acelerar seu desenvolvimento por meio de representaçôes rígidas de "normalidade". Ressaltase, assim, que a carência de recursos materiais e financeiros, já que as mães provinham de um contexto de baixa renda, não se mostrou um fator limitador do investimento materno para com o bebê e para a relação mãe-bebê. Embora seja fundamental possibilitar o acesso aos recursos básicos e a garantia de direitos às famílias e a suas crianças, o vínculo afetivo mãe-bebê, a capacidade de cuidar e de compreender o bebê parece responder a algo que ultrapassa explicações reducionistas, mas que responde, entre outros fatores, a uma disponibilidade interna da própria mãe para a relação com seu bebê.

Cabe ainda lembrar que todas as participantes do estudo eram mães que frequentavam o Programa da Criança, para acompanhamento do desenvolvimento de seu filho, desde o nascimento deste. Assim, pode-se supor que estas fossem mães mais atentas à saúde do filho e disponíveis do que aquelas mães que abandonaram o programa mais cedo ou nem mesmo chegaram a levar seus bebês para o acompanhamento inicial. Além disso, destaca-se que, 
com exceção de uma das mães, as demais não estavam trabalhando fora de casa quando participaram do estudo, de modo que podiam acompanhar de perto o desenvolvimento de seus filhos no dia a dia.

Também se destaca como originalidade e contribuição para a área a estratégia metodológica utilizada neste estudo, a qual partiu de um projeto de extensão realizado no Programa da Criança, em que os bebês e seus cuidadores eram acompanhados nos dois primeiros anos de vida. A partir dessa inserção, o estudo desenvolvido pela equipe de Psicologia possibilitou que essas mulheres falassem sobre a experiência de ser mãe e sobre o desenvolvimento de seus filhos. Pôde-se, assim, fortalecer o vínculo da equipe com essas díades e conhecer um pouco mais de suas realidades e, com isso, contribuir para o desenvolvimento infantil a partir de orientaçôes adequadas à realidade das famílias. Nesse sentido, este estudo retrata uma abordagem integrada de pesquisa e extensão, na qual a pesquisa aparece como resultado de uma aproximação com o campo e com os participantes. Para além desse aspecto, salienta-se também os procedimentos metodológicos que foram utilizados, ou seja, lançou-se mão de diversos recursos de acesso ao conhecimento, como entrevistas, observação na sala do programa, observação no domicílio e devolução dos resultados.

No momento da devolução, foi entregue as famílias um DVD com a filmagem da primeira observação, material que foi recebido com muita satisfação pelas participantes, que puderam compartilhar com seus familiares a experiência vivenciada, rompendo-se, assim, a distância entre o pesquisador e o participante. Por fim, como desdobramento dessa pesquisa, foi construída uma cartilha referente ao segundo ano de vida, a qual contém as categorias apresentadas neste artigo e está sustentada nas falas das participantes. $\mathrm{O}$ material foi construído em linguagem clara e de fácil acesso e está sendo utilizado no Programa da Criança, a fim de que as mães e demais familiares possam estar atentos aos aspectos que envolvem o segundo ano de vida. Evidencia-se, assim, a relevância de novas abordagens de pesquisa que possam se constituir em suporte para ações que estejam ancoradas na realidade a qual se destinam.

Ainda, considerando que, historicamente, os estudos e ações para a saúde da criança nos serviços públicos estiveram orientados por aspectos físicos e nutricionais, salienta-se a relevância de contribuições que enfoquem os aspectos emocionais do desenvolvimento infantil. Assim, destaca-se a importância da Psicologia nos serviços públicos de saúde, ampliando o olhar sobre o desenvolvimento infantil e investindo na promoção da saúde e no fortalecimento dos vínculos entre os profissionais e a díade mãe-criança. 


\section{REFERENCIAS}

Andrade, S. A., Santos, D. N., Bastos, A. C., Pedromônico, M. R. M., AlmeidaFilho, N. D., \& Barreto, M. L. (2005). Ambiente familiar e desenvolvimento cognitivo infantil: uma abordagem epidemiológica. Revista Saúde Pública, 39(4), 606-611.

Arnold, R. \& Colburn, N. (2011). It's never too early: first steps. School Library Journal, 20.

Barbour, R. (2009). Grupos focais. Porto Alegre: Artmed.

Bardin, L. (2010). Análise de conteúdo. Lisboa: Edições 70.

Belei, R., Gimeniz-Paschoal, S., Nascimento, E., \& Matsumoto, P. (2008). O uso de entrevista, observação e videogravação em pesquisa qualitativa. Cadernos de Educação, 30(1), 187-199.

Biaggio, A. (2003). Psicologia do desenvolvimento. Petrópolis: Vozes.

Bowlby, J. (2002). Apego e perda: apego: volume 1. A. Cabral (Trad.). São Paulo: Martins Fontes.

Brazelton, T. (1994). Momentos decisivos do desenvolvimento infantil. São Paulo: Martins Fontes.

Conselho Federal de Psicologia (2000, 20 dezembro). Resolução CFP $n^{o}$ 016/2000, de 20 de dezembro de 2000. Dispõe sobre a realização de Pesquisa em Psicologia com Seres Humanos. Brasília: CFP.

Conselho Nacional de Saúde. (2012). Resolução do Conselho Nacional de Saúde 466/12. Dispõe sobre as diretrizes e normas regulamentadoras de pesquisas envolvendo seres humanos. Brasília: CNS.

Dourado, S. J., Carvalho, S. A. S., \& Lemos, S. M. A. (2015). Desenvolvimento da comunicação de crianças de um a três anos e sua relação com o ambiente familiar e escolar. Revista Cefac, 17(1), 88-99.

Flores, D. B. (2012). Concepçôes dos profissionais sobre o desenvolvimento da linguagem de crianças no contexto da creche. (Dissertação de Mestrado). Universidade Federal do Paraná, Curitiba.

Gaskell, G. (2002). Entrevistas individuais e de grupos. In M. W. Bauer, \& G. Gaskell (Orgs.), Pesquisa qualitativa com texto, imagem e som: um manual 
prático. (pp. 64-89). Petrópolis: Vozes.

Gomes, R. (2001). A análise de dados em pesquisa qualitativa. In M. Minayo (Org.), Pesquisa social: teoria, método e criatividade. (pp. 67-80). Petrópolis: Vozes.

Lopes, R., Vivian, A., Oliveira, D., Silva, C., Piccinini, C., \& Tudge, J. (2009). "Quando eles crescem, eles voam": percepções e sentimentos maternos frente ao desenvolvimento infantil aos 18-20 meses. Psicologia em Estudo, 14(2), 221232.

Lopes, R., Vivian, A., Oliveira, D., Silva, C., Piccinini, C., \& Tudge, J. (2012). Sentimentos maternos frente ao desenvolvimento da criança entre 24 e 28 meses. Estudos de Psicologia, 29(Suppl. 1), 737-749.

Mahler, M. S. (1993). O nascimento psicológico da criança: simbiose e individuação. Porto Alegre: Artes Médicas.

Manfro, G. G., Maltz, S., \& Isolan, L. (2001). A criança de 0 a 3 anos. In C. Eizirik, F. Kapczinski, \& A. Bassols (Orgs.), O ciclo da vida humana: uma perspectiva psicodinâmica. (pp. 73-89). Porto Alegre: Artmed.

Mellier, D. (2013). L'agitation du très jeune enfant, une revue de la littérature. Neuropsychiatrie de l'Enfance et de l'Adolescence, 61(3), 160-165.

Newcombe, N. (1999). Desenvolvimento infantil: abordagem de Mussen. Porto Alegre: Artes Médicas.

Papalia, D. \& Olds, W. (2000). Desenvolvimento Humano. Porto Alegre: Artes Médicas.

Paula, L. de, Pires, C., Mascarenhas, T., Costa, J., \& Brito, L. (2013). Percepção da associação entre estimulação ambiental e desenvolvimento normal por mães de crianças nos três primeiros anos de vida. Revista Paulista de Pediatria, 31(2), 211-217.

Pereira, K. R. G., Saccani, R., \& Valentini, N. C. (2016). Cognição e ambiente são preditores do desenvolvimento motor de bebês ao longo do tempo. Fisioterapia e Pesquisa, 23(1), 59-67.

Richardson, R. J. (2008). Pesquisa social: métodos e técnicas. São Paulo: Atlas.

Weijer-Bergsma, E., Wijnroks, L., \& Jongmans, M. (2008). Attention 
development in infants and preschool children born preterm: a review. Infant Behavior \& Development, 31, 333-351. 